\title{
The Effect of Promotion Benefit Level on Patronage Intention in Limited-quantity Promotion: A Consumer Perceived Availability Perspective
}

\author{
Jun Ding, Qiang Lu and Jiaoju Ge* \\ Harbin Institute of Technology Shenzhen Graduate School \\ haveding@gmail.com; qiang.lu.home@gmail.com; *jiaoge@hitsz.edu.cn
}

\begin{abstract}
This study aims to investigate the effect of promotion benefit level on consumers' patronage intention in limited-quantity promotion $(L Q P)$ by considering the mediating influence of perceived availability. A mathematical model is built and an experiment is conducted to demonstrate that the effect of promotion benefit level on patronage intention is reversed $U$-shaped in LQP. When promotion benefit level is low, patronage intention increases as promotion benefit level increases, whereas when promotion benefit level is high, patronage intention would decrease as promotion benefit level increases. The mediating influence of perceived availability between promotion benefit level and patronage intention explains this phenomenon. Empirical results show that perceived availability is negatively related with promotion benefit level and patronage intention is positively related with perceived availability. Those results can be used by retailers to determine the most appropriate benefit level in $L Q P$.
\end{abstract}

Keywords: patronage intention, promotion benefit level, perceived availability, limitedquantity promotion

\section{Introduction}

There is always news about consumers who rush into stores to purchase the promoted product in China. On Jan 5 2015, an old man run down an old woman when he run to purchase the discounted eggs[1]. On Dec 18 2014, Jonathan Meador and Jonathon Lim took a series of pictures describing the scene that hundreds of Chinese people rush into a supermarket to take advantage of promotional offers[2]. Therefore, imagining that Jack is sitting at home, reading about a promotion. This is that the twenty-five percent discount promotion is only available for 100 pieces of Kindle Paperwhite. He wishes to spend one hour to the store and back to take advantage of the promotional offer if he can purchase the discounted Kindle Paperwhite. However, when he thinks of the possibility that the product may be sold out when he arrives at the store, he hesitates. This paper aims to investigate the effect of promotion benefit level on consumers' patronage intention in limitedquantity promotion (LQP) through the mediating influence of perceived availability.

LQP is available with a predefined quantity of promoted product[3]. LQP was shown to be very effective on increasing consumers' preference toward the promoted product[4] and speeding consumers' purchasing decision[5; 6]. The effectiveness of LQP on consumer preference and purchase intention is more obvious for men than women[7]. In order to take advantage of the promotional offer, consumers have to buy the product before other consumers do. This means they have to compete with other consumers to purchase the product[5].

Promotion benefit level is surely one of the main factors that influence the appeal of promotion [8;9]. The higher of the promotion level, consumers would be more willing to visit the store $[10 ; 11]$. However, when the seller limits the quantity of 
product in LQP, thus deliberately causes stockout situation, consumers would take the possibility that they cannot buy the promoted product into consideration more seriously [6]. They would weigh the cost and corresponding benefit $[12 ; 13]$.

The objective of this study is to investigate the influence of promotion benefit level on consumers' patronage intention through the mediating role of perceived scarcity. Based on the results of an experiment carried out on the Internet in China, we demonstrate that the effect of promotion level on consumers' patronage intention is reversed u-shaped such that when promotion benefit level is low, consumers' patronage intention would increase with promotion benefit level. While when promotion benefit is high, consumer's patronage intention would decrease with promotion benefit level. Consumers' perceived availability mediates the effect of promotion level on patronage. These findings can be used by retailers to better understand the effectiveness of LQP in attracting consumers to visit store when considering the effect of promotion benefit level.

The structure of this paper is arranged as follow. First, we discuss the theory, model and central propositions, which are followed by two experiments to examine those propositions. Then, we discuss the limitations and directions for future research. At last, we give some suggestions for management.

\section{Theory, Model, and Central Propositions}

\subsection{Perceived Availability}

Perceived availability is a perception of product availability experienced by consumers for a particular product ahead of knowing the fact that whether or not they can buy the product. Perceived availability is different from perceived scarcity. Scarcity effect would increase the distinctiveness of the product, thus enhance the attractiveness of the product [7;14] and speed consumers' purchasing decision [5]. However, perceived availability is not related with the product, but related with the appeal of the promotion [15].

In LQP, the quantity of product that the seller with to give out is fixed. The promoted product would be out-of-stock when it is sold out and the vendor does not ensure the availability of the product. Consumers have to compete with other consumers in order to take advantage of the promotional offer [5], which means that they must buy the product before other consumers do. When they're at home, consumers could not be sure that they can buy the product when they arrive at the store. In the case that the promotion benefit level is high, consumers would expect that more other consumers would also desire to take advantage of promotional offer[16], thus the competition would be so fierce that the possibility of purchasing the product successfully is very low[17]. Therefore, we assume that as promotion benefit level increases, which increases the attractiveness of the promotion, consumers' perceived availability of the promoted product is lowered.

H1: Perceived availability is negatively related with promotion benefit level.

\subsection{Reportage Intention}

When consumers are considering whether or not to visit a store to take advantage of a promotional offer, they would weigh the time and effort spent to visit the store and money saving $[12 ; 18]$. Consumers would evaluate time by the after-tax pay wage rate [19]. Recent researches also demonstrated that money and time have psychologically distinct characteristics that would affect consumers' decision [20; 21].

Money-saving increases with promotion benefit level. Therefore, consumers' utility of visiting the store would increase with promotion benefit level. However, as 
promotion benefit level increases, it's posited that perceived availability would decrease. When consumers cannot be certain that they can buy the promoted product in LQP, their expectation of utility they can get by visiting the store would decreases. Therefore, the effect of higher promotion level on consumers' expected utility would be neutralized by consumers' perceived availability.

Base on the discussion about consumers' decision between time and money, we build the following consumer choice model based on [18]. We assume that consumers receive the utility $b_{0}\left(b_{0}>0\right)$ from consuming the product. Travel time spent to visit the store is $T$. Product's original price and benefit level is $P_{0}$ and $P_{b}$, respectively. Promotion price would be $P_{0}-P_{b}$.

Consumer utility $(U)$ from visiting the store to buy the product is divided into two additive components: deterministic component $(V)$ and random component $(\varepsilon)$. If the promoted product is available when consumers arrive at the store, the deterministic component $\left(V_{\text {available }}\right)$ would be:

$V_{\text {available }}=b_{0}-b_{1}\left(P_{0}-P_{b}\right)-b_{2} T$

Where $b_{1}\left(b_{1}>0\right)$ and $b_{2}\left(b_{2}>0\right)$ indicate consumers' price sensitivity and time sensitivity, respectively.

If the product is sold out when consumers reach the store, the deterministic component $\left(V_{\text {stockout }}\right)$ would be:

$V_{\text {stockout }}=-b_{2} T$

Before setting out for the store, consumers' expectation of deterministic component of utility $E(V)$ would be:

$E(V)=\theta V_{\text {available }}+(1-\theta) V_{\text {stockout }}=\theta\left[b_{0}-b_{1}\left(P_{0}-P_{b}\right)\right]-b_{2} T$

$\theta(0 \leq \theta \leq 1)$ is perceived availability of the promoted product.

If we take the derivative of $E(V)$ with respect to $\theta$, we get

$\partial E(V) / \partial \theta=b_{0}-b_{1}\left(P_{0}-P_{b}\right)>0$

The above quantity is positive because the underlying assumption is the utility that consumers can get by consuming the product exceeds their willingness to possess the money.

We assume that consumers either visit the store or not. Therefore, we model consumers' decision about whether visiting the store as binary logit specification. The probability of visiting the store $P$ is

$P_{r}=e^{E(V)} /\left(1+e^{E(V)}\right)$

Then we take the derivative of $P_{r}$ with respect to $\theta$, we can get:

$\frac{\partial P_{r}}{\partial \theta}=\frac{e^{E(V)}}{\left(1+e^{E(V)}\right)^{2}} * \frac{\partial E(V)}{\partial \theta}>0$

The above quantity is also positive. When consumers are more certain that they can purchase the promoted product, their expected utility of visiting the store is higher. As consumers' expectation of the utility by visiting the store decreases, their willingness of visiting the store decreases. Therefore, we propose the second assumption that patronage intention is would increase as perceived availability increases.

H2: Patronage intention is positively related with perceived availability.

We assume that $\theta_{0}$ is the perceived availability when the product isn't on promotion $\left(0<\theta_{0} \leq 1\right)$. According to $\mathrm{H} 1$ that perceived availability is negatively related with promotion benefit level, $\partial \theta / \partial P_{b}<0$, we assume that $\theta=\theta_{0}+$ 
${ }_{c} P_{b}(c>0)$, where $c$ is the margin of perceived availability when promotion benefit level rises. In this way, $E(V)$ can be expressed as:

$$
E(V)=\left(\theta_{0}+c P_{b}\right)\left[b_{0}-b_{1}\left(P_{0}-P_{b}\right)\right]-b_{2} T
$$

Then we take the derivative of $E(V)$ with respect to $P$, we get

$$
\partial E(V) / \partial P_{b}=c\left(b_{0}-b_{1} P_{0}\right)+\theta_{0} b_{1}+2 b_{1} c P_{b}
$$

In order to decide the point at which consumers' patronage intention is the highest, we take the derivative of $P_{r}$ with respect to $P_{b}$, we can get:

$$
\frac{\partial P_{r}}{\partial P_{b}}=\frac{e^{E(V)}}{\left(1+e^{E(V)}\right)^{2}} * \frac{\partial E(V)}{\partial P_{b}}
$$

When we make $\partial P_{r} / \partial P_{b}$ equals to zero, correspondingly, $\partial E(V) / \partial P_{b}$ equals to zero, we can get:

$$
P_{b}^{*}=\frac{2 b_{1} c}{c\left(b_{1} P_{0}-b_{0}\right)-\theta_{0} b_{1}}
$$

When $P_{b}<P_{b}^{*}, \partial P_{r} / \partial P_{b}<0, P_{r}$ would decrease when $P_{b}$ increases. While when $P_{b}>P_{b}^{*}, \partial P_{r} / \partial P_{b}>0, P_{r}$ would increase when $P_{b}$ increases. Only at the point of $P_{b}^{*}$, consumers can form the most expectation of utility by visiting the store.

When the promotion level is low, the promotion would not be attractive to consumers such that consumers' willingness to visit the store is low. However, when the promotion level is so high that the promotion is attractive to most consumers, the competition of taking advantage of the promotional offer is so intense that the possibility of successfully purchasing the product has only a slim chance. Consumers would lower their intention to patronage the store to take advantage of the promotional offer.

H3: The effect of promotion benefit level on patronage intention is reversed Ushaped, such that when promotion benefit level is low, patronage intention is lower than when promotion benefit level is medium, while when promotion benefit level is high, patronage intention is lower than when promotion benefit level is medium.

The perceptual model is shown in Figure 1. We hypothesized the negative effect of promotion benefit level on perceived availability and the positive effect of perceived availability on patronage intention. We also hypothesized that promotion benefit level moderates the effect between promotion type and perceived availability and the effect between perceived availability and patronage intention.

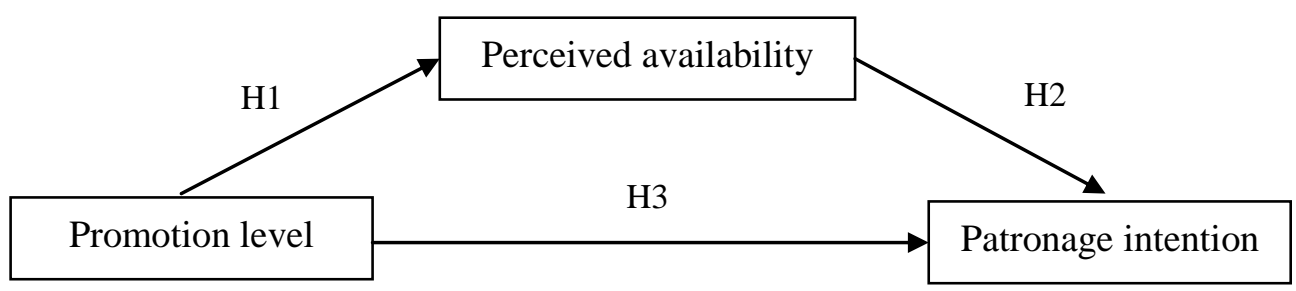

Figure 1. Perceptual Model and Hypotheses

\section{Experiment}

\subsection{Method}

Design A $2 \times 1$ between subject experiment that consists of different promotion benefit levels (low:10\%, medium: 30\%, high: 50\%) was administrated. Specific promotion benefit levels were established based on previous literature $[8 ; 22]$ and a 
review of price discounts in marketplace. Promotion benefit level was manipulated in the scenario.

Stimuli. Five graduate students generated a list of products that were usually promoted using "limited quantity" style promotion. Six products (peanut oil, detergent, white wine, wheat powder, milk and soft drink) in this list were evaluated for relevance by 30 participants on the Internet. They were asked the likelihood of seeing each product being sold by "limited quantity" style promotion in local market (not likely at all/very likely). Based on their responses, peanut oil was chosen as stimulus in the experiment. Peanut oil is a main kind of eligible oil consumed by Chinese people. There is not much difference between different brands of peanut oil, and purchasing them would not require emotional involvement. Therefore, we could exclude the influence the effect of brands, product quality etc.

Dependents measurement.Adopted from prior study, perceived availability was measured using "How certain do you feel that the product will be available when you arrive at the store" (1=not at all certain, $7=$ definitely certain)[18]. Patronage intention was measured by two seven-point scales ("The likelihood that I would visit this store to buy the peanut oil is very high" and "I would be willing to go to this store to buy the peanut oil")[23; 24].

Pretest. In order to make sure the quantity of LQP would cause adequate consumers' perceived availability[5], we administrated an interview with four experts from academy and three experts from retailing industry, two experiments by asking participants to assess the quantity of LQP that a supermarket can sell in one day and answered by open-ended question $(\mathrm{N}=30)$ or close-ended question $(\mathrm{N}=31$, numbers were $20,50,100,150,200,250$ and 300 ). The mean values of the three pretests were 113.5, 107.2 and 98.7 respectively. Therefore, 100 pieces of peanut oil in LQP would be the equal quantity of a peanut oil that a supermarket can sell in one day.

Participants. Participants were recruited from China's biggest service trading website, Zhubajie. Each participant was rewarded one Yuan. Recruiting information and a link to the experiment was posted on the website. When participants clicked the link, they were redirected to the study. In this way, participants were from all cross China and with wide age range. IP address and nickname were used to make sure that each participant can take part in the experiment once. Time spent to complete the experiment and manipulation check questions in the end were used to control the quality of the experiment. We promised that two participants would be randomly chosen as lucky men and each one can get one bottle of peanut oil after the experiment. This is used to increase the involvement of participants in the experiment.

Procedure. Participants were asked if they had purchased eligible oil in the past one month and/or intend to purchase one in the next month. This was designed to include considered buyers (effective or potential) only in the experiment. Those who answered positive were then directed to the survey and randomly assigned to one of the experiment conditions. They were provided with the following scenario: "Imaging when reading a leaflet at home on a Saturday morning, you notice that a kind of peanut oil is on promotion in store X. Based on the information on the leaflet and your past experience, you can form conclusion of the promotion as follow: selling price (ordinary price: 100 Yuan; promotional price: 90,75 or 50 Yuan), promotion type (limited-quantity promotion: only for 100 pieces), and travel time to the store and back (one hours)". After reading the scenario, they provided their certainty of purchasing the product successfully and their willingness to visit the store to take advantage of the promotional offer. Then, they provided gender and age for demographic description. At last, they completed the manipulation check questions. 


\subsection{Results}

Manipulation check. Finally, 199 participants took part in the experiment in two weeks, with $43.7 \%$ male and $56.3 \%$ female and average age of 27 . Manipulation check indicated that all participants correctly identified the corresponding promotion type. Participants assigned to higher promotion level thought the promotion level is higher than participants assigned to lower promotion level $\left(M_{10 \%}=3.15, M_{25 \%}=4.81, M_{50 \%}=4.96, F(1,196)=9.13, p=.000\right)$.

Hypotheses tests. An ANOVA was performed on perceived availability with experimental group as independent variable. Perceived availability decreased when promotion benefit level increased $\left(M_{\text {low }}=4.52, M_{\text {medium }}=4.44, M_{\text {high }}=3.80, F(1\right.$, 196) $=3.922, p=.021)$, which supported H1. Linear regress result indicated that patronage intention was positively related with perceived availability $(B=.50, F(1$, 197)=61.097, $p=.000$ ), which supported H2.

Another ANOVA test was performed on patronage intention with experimental group as independent variable showed that the effect of promotion benefit level on patronage was significant $\left(M_{\text {low }}=3.43, M_{\text {medium }}=3.97, M_{\text {high }}=3.40, F(1,196)=2.35\right.$, $p=.098$ ), which supported H3 and was shown in Figure 2.

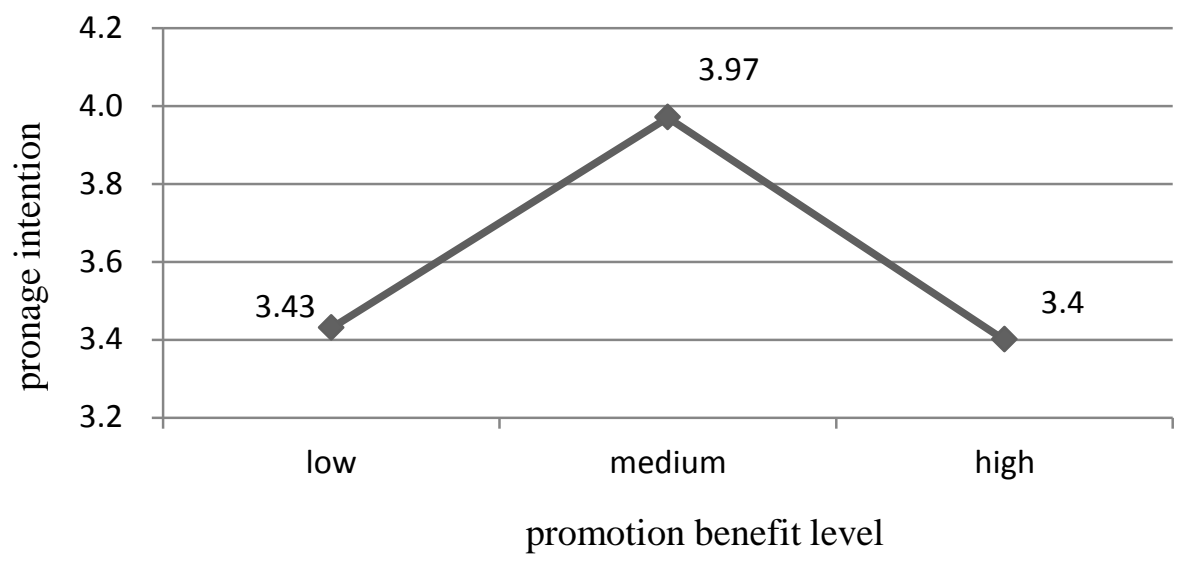

Figure 1. The Influence of Promotion Benefit Level on Patronage Intention

\subsection{Discussion}

As hypothesized, perceived availability was shown to be negatively related with promotion benefit level and patronage intention was positively related with perceived availability. Therefore, perceived availability was shown to mediating the effect of promotion benefit level on patronage intention [25]. The effect of promotion benefit level on patronage intention is reverse $\mathrm{U}$-shaped. When promotion benefit level was low or high, consumers' patronage intention was lower than when promotion level was medium in LQP.

\section{General Discussion}

LQP is commonly used as a tool to attract consumers and promote sales. However, because retailer limits the quantity of the product, consumers who arrive at the store when the promoted product is sold out would not be able to take advantage of the promotional offer. When there is quantity restriction on promotion, the attractiveness of promotion would not increase with benefit level as usual.

We investigated the effect of promotion benefit level on patronage intention and the mediating influence of perceived availability. Through a mathematic reasoning 
and an experiment conducted on the Internet, we have shown that as promotion benefit level increase, consumers would lower their expected possibility of purchasing the promoted product. As consumers lower the possibility of purchasing the product, they also lower their intention to patronage the store. As a result, even though higher promotion benefit level would increase the attractiveness of promotion when the benefit level is low, when the promotion benefit level exceeds a level, consumers' patronage intention would decrease with promotion benefit level.

\section{Implications for Executives}

Because when the promotion benefit level is too high, consumers would lower their expectation of purchasing the promoted product, which lower their intention to patronage the store. If retailers want to attract consumers to visit the store with LQP, it would be better that the promotion benefit level is not too high so that consumers would think they can buy the promoted product, therefore, increase their intention to patronage the store.

In LQP, consumers perceive the possibility of their successfully purchasing the product is low when the promotion benefit level is high, thus lower their intention to patronage the store. Therefore, in order to counter the adverse effect of perceived availability and increase consumers' intention to patronage the store, retailers can increase consumers' perceived availability. For example, retailers can set the quantity of LQP larger so that the promoted product would be available for a longer time. Instead of giving out the entire promoted product at one time, retailers can give out the promoted product at several times so that consumers who arrive at the store at later times can also have the chance of purchasing the promoted product.

\section{Limitations and Future Research}

The findings of our study must be interpreted in light of some limitations of the study, which can suggest useful directions for future studies. First the experiment was conducted online and participants were recruited online. For this reason, elder people who are more likely to take advantage of promotional offers but are not familiar with the Internet cannot participant in the study. However, participants' age in this study ranges from 17 to 55. This is even better than prior studies that were conducted in the classroom.

Second, even if promotion benefit level is the same, the amount of price deduction is higher with high-priced product than low-priced product[25]. Therefore, even with the same promotion benefit level, consumers would act more favorably toward a higher priced product because of the higher money saving [27]. Price level is a possible moderating factor between promotion benefit level and patronage intention when considering the mediating influence of perceived availability. Product type is one of the most important factors that would influence consumers' purchasing behavior[28]. Future research could explore the moderating influence of price level and product category between promotion benefit level and patronage intention.

We set the time that consumers have to spend to visit the store as an hour in the experiment. In China, as a developing world, only a few people own cars. The main method that people go to stores is by walking or bus, which is different from developed countries, in which people mainly drive to stores. Additionally, if the store nears consumer's home, consumers would be more likely to visit the store to take a chance because of the low cost of time and effort. Therefore, we expect that future research can be implemented in developed country to investigate the relationship between promotion benefit level and patronage intention and when the store is not far away. 


\section{Acknowledgments}

We acknowledge the support of the National Natural Science Foundation of China(Grant NO. 71171064) and Shenzhen Key Laboratory of Urban Planning and Decision Making of Shenzhen Graduate School, Harbin Institute of Technology.

\section{References}

[1] Y. Shi, "An old man who runs down an old women when rushing for discounted eggs compensates for fifty thousand Yuan ", http://newspaper.jfdaily.com/isdb/html/2015-01/13/content_1191464.htm, (2015).

[2] Unkown, "The scene in foreigners' camera of chinese people rush into supermarket", http://www.hiwxw.com/news/shehui/717_5.html, (2014).

[3] R. B. Cialdini, "Influence: Science and practice", Boston, MA: Pearson education, (2008).

[4] S. Swami and P. J. Khairnar, "Diffusion of products with limited supply and known expiration date", A Marketing Letters, vol. 14, no. 1, (2003), pp. 33-46.

[5] P. Aggarwal, S. Y. Jun and J. H. Huh, "Scarcity messages: A Consumer Competition Perspective", Journal of Advertising, vol. 40, no. 3, (2011), pp. 19-30.

[6] S. Gupta, "The psychological effects of perceived scarcity on consumers' buying behavior", University of Nebraska, Lincoln, (2013).

[7] H. Yoon, D. R. Chang and K. Lee, "It has to be ME (not YOU): The role of competitive message on the effectiveness of sales promotion", Journal of Global Scholars of Marketing Science, vol. 24, no. 3, (2014), pp. 1-11.

[8] E. N. Berkowitz and J. R. Walton, "Contextual influences on consumer price responses: An experimental analysis", Journal of Marketing Research, vol. 17, no. 8, (1980), pp. 349-358.

[9] M. Palazon and E. D. Ballester, "The expected benefit as determinant of deal-prone consumers' response to sales promotions", Journal of Retailing and Consumer Services, vol. 18, no. 6, (2011), pp. 542-547.

[10] P. Kotler and G. Armstrong, "Principles of Marketing 15th Global Edition", London: Prentice Hall, (2013).

[11] P. R. Darke and C. M. Chung, "Effects of pricing and promotion on consumer perceptions: It depends on how you frame it", Journal of Retailing, vol. 81, no. 1, (2005), pp. 35-47.

[12] R. Saini, R. S. Rao and A. Monga, "Is that deal worth my time? The interactive effect of relative and referent thinking on willingness to seek a bargain", Journal of Marketing, vol. 74, no. 1, (2010), pp. 3448.

[13] H. Marmorstein, D. Grewal and R. P. Fishe, "The value of time spent in price-comparison shopping: Survey and experimental evidence", Journal of Consumer Research, (1992), pp. 52-61.

[14] H. H. Ku, C. C. Kuo and T. W. Kuo, "The effect of scarcity on the purchase intentions of prevention and promotion motivated consumers", Psychology \& Marketing, vol. 29, no. 8, (2012), pp. 541-548.

[15] K. R. Evans, T. Christiansen and J. D. Gill, "The impact of social influence and role expectations on shopping center patronage intentions", Journal of the Academy of Marketing Science, vol. 24, no. 3, (1996), pp. 208-218.

[16] R. Suri, C. Kohli and K. B. Monroe, "The effects of perceived scarcity on consumers' processing of price information", Journal of the Academy of Marketing Science, vol. 35, no. 1, (2007), pp. 89-100.

[17] A. M. Bozzolo and T. C. Brock, "Unavailability effects on message processing: A theoretical analysis an empirical test", Basic and Applied Social Psychology, vol. 13, no. 1, (1992), pp. 93-101.

[18] D. Grewal, P. Kopalle, H. Marmorstein and A. L. Roggeveen, "Does travel time to stores matter? The role of merchandise availability", Journal of Retailing, vol. 88, no. 3, (2012), pp. 437-444.

[19] G. S. Becker, "A theory of the allocation of time", The economic journal, vol. 75, no. 299, (1965), pp. 493-517.

[20] C. Mogilner and J. Aaker, "the time vs. Money effect" : Shifting product attitudes and decisions through personal connection", Journal of Consumer Research, vol. 36, no. 2, (2009), pp. 277-291.

[21] R. L. Soster, A. Monga and W. O. Bearden, "Tracking costs of time and money: How accounting periods affect mental accounting", Journal of Consumer Research, vol. 37, no. 4, (2010), pp. 712-721.

[22] D. M. Hardesty and W. O. Bearden, "Consumer evaluations of different promotion types and price presentations: The moderating role of promotional benefit level", Journal of Retailing, vol. 79, no. 1, (2003), pp. 17-25.

[23] D. Grewal, J. Baker, M. Levy and G. B. Voss, "The effects of wait expectations and store atmosphere evaluations on patronage intentions in service-intensive retail stores", Journal of Retailing, vol. 79, no. 4, (2003), pp. 259-268.

[24] M. Kim and S. J. Lennon, "Consumer response to online apparel stockouts", Psychology \& Marketing, vol. 28, no. 2, (2011), pp. 115-144.

[25] D. P. MacKinnon, C. M. Lockwood, J. M. Hoffman, S. G. West and V. Sheets, "A comparison of methods to test mediation and other intervening variable effects", Psychological methods, vol. 7, no. 1, (2002), pp. 83-104. 
[26] D. Grewal, H. Marmorstein and A. Sharma, "Communicating price information through semantic cues: The moderating effects of situation and discount size", Journal of Consumer Research, (1996), pp. 148155.

[27] T. Boyaci and S. Ray, "Product differentiation and capacity cost interaction in time and price sensitive markets", Manufacturing \& Service operations management, vol. 5, no. 1, (2003), pp. 18-36.

[28] L. M. Sloot, P. C. Verhoef and P. H. Franses, "The impact of brand equity and the hedonic level of products on consumer stock-out reactions", Journal of Retailing, vol. 81, no. 1, (2005), pp. 15-34.

\section{Authors}

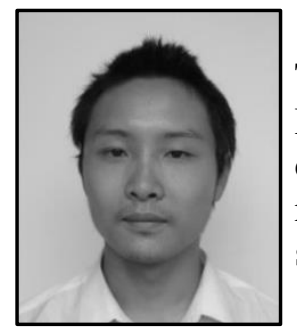

Jun Ding, he is a Ph.D candidate at Harbin Institute of Technology Shenzhen Graduate School, China. Majored at Managerial Science and Engineering. Main research area includes consumers' purchasing behavior when product is out-of-stock, retailers' ways to alleviate consumers' negative emotion in stockout situation and consumers' response to perceived availability.

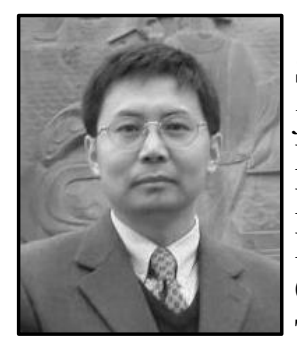

Qiang Lu, he is a Professor at Harbin Institute of Technology Shenzhen Graduate School, China. Published papers in many famous journals, including Information Sciences, International Journal of Production Economics, International Journal of Operations and Production Management, International Journal of Production Research, Service Industries Journal, Journal of Risk Research, Chinese Management Studies, International Journal of Sustainable Transportation and so on.

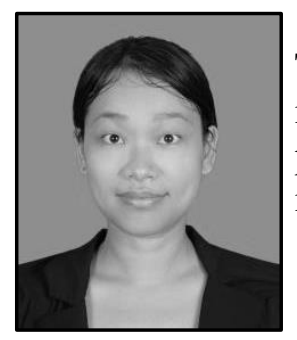

Jiaoju Ge, she is an Associate Professor at Harbin Institute of Technology Shenzhen Graduate School, China. Main research area is marketing and economic policy, includes policy analysis, consumer preferences, marketing-finance interface, branding and online marketing. Published papers in many famous journals. 
International Journal of $u-$ and e- Service, Science and Technology Vol.8, No. 12 (2015) 